\title{
The state-of-play and future of platinum drugs
}

\author{
Michael G Apps, Eugene H Y Choi and Nial J Wheate
}

Faculty of Pharmacy, The University of Sydney, Sydney, New South Wales 2006, Australia

Correspondence

should be addressed

to $\mathrm{N} J$ Wheate

Email

nial.wheate@sydney.edu.au

\begin{abstract}
The year 2015 marks the 50th anniversary since the discovery of the anticancer potential of cisplatin and it remains just as useful now as it did back then, especially for the treatment of some endocrine-related cancers like ovarian and testicular carcinomas. Since its discovery, five other platin drugs have received approval in various countries. While several new platin drugs are in preclinical development, in the last decade only two new platin drugs have entered clinical trials, LA-12 and dicycloplatin, reflecting a shift in research focus from new drug design to improved formulations of already approved platin drugs. These formulations include their encapsulation with macrocycles to slow and prevent their degradation by proteins and peptides; their attachment to nanoparticles to passively target solid tumours through the enhanced permeability and retention effect and their coordination to important nutrients, proteins, antibodies and aptamers for active tumour targeting. These formulation methods have all shown potential but none have yet yielded a new marketable medicine containing a platin drug. The reasons for this are problems of consistent drug loading, controlling the location and timing of drug release and the inherent toxicity of some of the drug delivery vehicles. In addition to drug delivery, functional genomics is now playing an increasing role in predicting patients' responses to platin chemotherapy and their likelihood of experiencing severe side effects.
\end{abstract}

\author{
Key Words \\ - cancer \\ - cisplatin \\ - formulation \\ - drug delivery \\ - functional genomics
}

\section{Introduction}

While cisplatin was first synthesised in 1844, the anticancer potential of cisplatin was not discovered by accident until 1965 (Kauffman et al. 2010). It was approved for use in 1978 and since then another 25 platin drugs have entered clinical trials, with two, oxaliplatin and carboplatin, gaining broadly worldwide approval and another three gaining approval in single markets; nedaplatin in Japan, lobaplatin in China and heptaplatin in Korea (Wheate et al. 2010) (Fig. 1).

Despite a claim that $50-70 \%$ of all patients receive a platinum drug (Sava \& Dyson 2006), which has been repeated by others (Harper et al. 2010, Zalba \& Garrido
2013), there is no evidence on how many patients actually receive these drugs. Only the overall number of chemotherapy regimens that include a platin drug is known with any accuracy; based on Martindale and the Australian EviQ database, $\sim 50 \%$ of all chemotherapy schedules include a platinum drug (Wheate etal. 2010). Platinum drugs are used to treat a wide variety of cancers, including some endocrinerelated cancers: testicular and ovarian carcinomas. They are also used to treat melanoma, small-cell and non-small-cell lung cancer, myelomas and lymphomas.

The generic names of all platinum-based drugs end with 'platin', and henceforth, this abbreviation will be

Published by Bioscientifica Ltd. 
<smiles>N[PH](N)(Cl)Cl</smiles>

Cisplatin<smiles>N[P+]1(N)OCC(=O)O1</smiles>

Nedaplatin (Japan)<smiles>N[PH]1(N)OC(=O)C2(CCC2)C(=O)O1</smiles>

Carboplatin<smiles>O=C1O[P]2(N[C@H]3CCCC[C@H]3N2)OC1=O</smiles>

Oxaliplatin

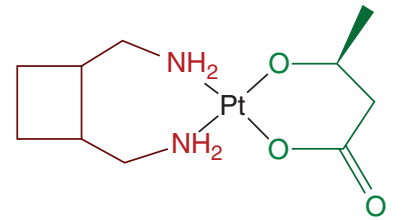

Lobaplatin (China)

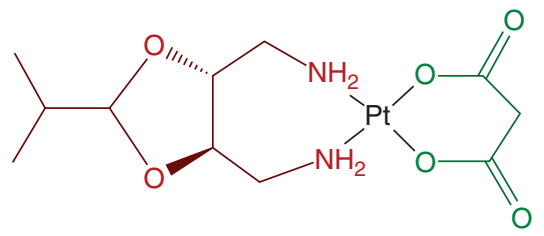

Heptaplatin (Korea)

Figure 1

The structures of the approved platin drugs, showing the carrier a $(\mathrm{m})$ mine ligands in red and the labile chloride or carboxylate-based ligands in green. All platins act as prodrugs, requiring replacement of their labile ligands with water before they are able to bind and disrupt the function of DNA.

used in this review to refer to platinum drugs in general. The beginning of platinum drug names are based on the configuration of the drugs' ligands (e.g., cisplatin and transplatin refer to the different chirality of the chloride ligands) or can come from the name of the ligands used (carboplatin contains a dicarboxylate ligand, oxaliplatin contains an oxalate ligand and triplatin contains three platinum cations).

Platin drugs contain two types of ligands attached to a central platinum cation. These are amine or ammine carrier ligands and labile chloride or carboxylate ligands (Fig. 1). To bind their target, nuclear DNA, platins act as prodrugs and require aquation of their labile ligands within cancer cells so that they can form bonds with the N7 atom on guanine and adenosine bases. Such binding stops DNA replication and transcription, which then initiates cellular apoptosis (Dasari \& Tchounwou 2014).

Despite their success, platin drugs have two main limitations: their severe side effects and the ability of cancers to develop drug resistance. The side effects arise from their indiscriminate attack on all rapidly dividing cells. Common side effects of platin drugs include nausea and vomiting, diarrhoea, myelosuppression, neuropathy, ototoxicity, hepatotoxicity and nephrotoxicity. These side effects can be so severe that they limit the dose that can be administered to patients (Ruggiero et al. 2013). As such, many tumours are treated with sub-lethal doses of platin drug, thus giving the cancers a chance to develop resistance.

Platin resistance arises via four main mechanisms: reduced cellular uptake and upregulated drug efflux from cells, increased degradation and detoxification of the drugs inside the cells by glutathione, reduced formation of drug-DNA adducts and an increased tolerance or repair of the damaged DNA (Galluzzi et al. 2012).

New platin drugs continue to be developed, with two drugs currently under commercial preclinical development and two other drugs undergoing clinical trials. These drugs are largely designed to be either more cytotoxic to cancer cells compared with cisplatin and/or to be able to overcome cisplatin drug resistance. Alongside drug design, a lot of research into platins in the last 15 years has focused on new formulations that can either prevent drug degradation or better target tumours via passive or active mechanisms.

Oncology is now entering the era of personalised medicine, where doctors will select the best treatment for each patient after extensive genotyping of both the patient and the tumours. Such screening allows doctors to select the drugs that are most likely to be effective for each individual patient and, just as importantly, be able to predict the severity of the side effects the patient is likely to experience. Platins are not being left behind and research is now being undertaken to use functional genomics to inform drug selection.

In this paper we review the current status of platin drugs with a focus on both the development of new small molecule agents as well as new formulations to improve drug stability and targeting with the advantages and limitations of each system discussed. Finally, the stateof-play of functional genomics in platin drug selection for patients is examined, focusing on what has already been done and where we think it will develop in the future.

Published by Bioscientifica Ltd. 


\section{New drugs in preclinical development and under clinical evaluation}

\section{Dicycloplatin}

Dicycloplatin is a reformulation of the drug carboplatin by Sopo-Xingda Pharmaceutical and Bioplatin AG and is currently under clinical trial evaluation in China. The formulation contains an extra carboxylate ligand that is hydrogen-bonded to the drug in the solid state (Fig. 2). When dissolved in water, the extra ligand makes carboplatin more stable by slowing the rate at which the drug is aquated.

The first human trials of dicycloplatin were completed in 2003 with phase I trials indicating a safety profile similar to carboplatin. The maximum tolerated dose is $550 \mathrm{mg} / \mathrm{m}^{2}$, with a recommended dose of $450 \mathrm{mg} / \mathrm{m}^{2}$ once every three weeks (Yu et al. 2014). In comparison, carboplatin is delivered in a dose between 300 and $450 \mathrm{mg} / \mathrm{m}^{2}$ every three to four weeks depending on the treatment regimen used (Brayfield 2015).

The results of one phase II trial of dicycloplatin have been reported. In a double-blinded trial comparing dicycloplatin and paclitaxel against carboplatin and paclitaxel in non-small cell lung cancer, the results indicate that there was no significant difference in patient outcomes between the two trial arms (Liu et al. 2014). There is a claim to another phase II trial completed around
2003 for small cell lung cancer (reference 7 in (Yu et al. 2014)), although there is no mention of this paper on the journal's website.

\section{LA-12}

This drug is a platinum(IV) prodrug that requires intracellular reduction to platinum(II) by glutathione and ascorbate (Wexselblatt \& Gibson 2012), as well as aquation of its chloride ligands, before it can bind DNA (Fig. 2). The high activity of the drug is partially attributed to its lipophilic ligands. These include the adamantylamine carrier ligand, which is similar in chemical structure to the approved Alzheimer's drug, memantine, and the drug's axial acetate groups that are released upon reduction to platinum(II) (Kozubík et al. 2005). While the drug has entered clinical trials, there are as yet no published findings from phase I or phase II, although there is some data correlating serum protein binding in animal models to samples taken from patients (Bouchal et al. 2011).

\section{Phosphaplatins}

This is a family of platin drugs under preclinical development by Phosplatin Therapeutics (USA). These drugs are based on the structures of cisplatin and

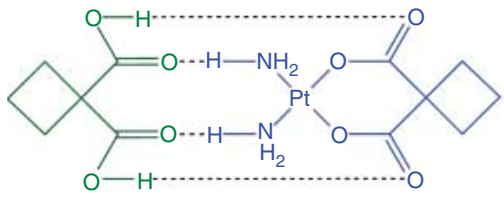

Dicycloplatin

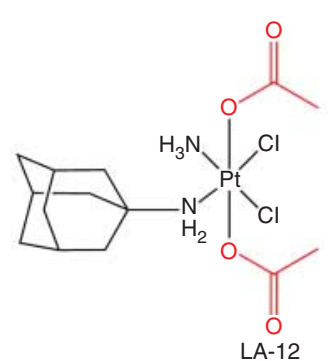<smiles></smiles>

Phosphaplatins

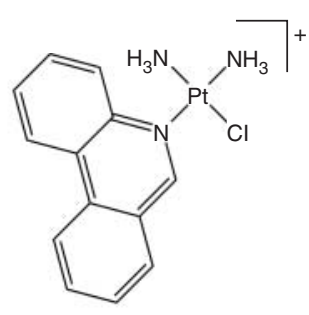

Phenanthriplatin

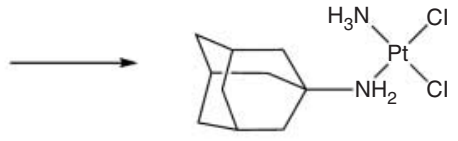

LA-12 after intracellular reduction

\section{Figure 2}

The chemical structures of the platin drugs under preclinical and clinical development. For dicycloplatin, the original carboplatin drug molecule is indicated in blue with the additional carboxylate-stabilising ligand shown in green. The hydrogen bonds of dicycloplatin that hold the free ligand to the drug are shown as dashed lines. Also shown is the active component of
LA-12 after the loss of its axial ligands (shown in red) when it is reduced from platinum(IV) to platinum(II) within cancer cells. A * indicates a chiral centre: either $R$ or $S$. Counter ions for phenanthriplatin are not shown but are potentially chloride or nitrate. 
oxaliplatin where the labile ligands of the parent drugs have been replaced by a single pyrophosphate ligand (Fig. 2). Unlike normal platins, these drugs don't appear to act by binding to DNA and the phosphate ligands remain bound to the drug even after prolonged periods (Moghaddam et al. 2011). The drugs still induce cellular apoptosis, although they are specific to the S and G2 phases of the cell cycle and are highly active both in vitro and in vivo against human cancer cell lines that are both sensitive and resistant to cisplatin (Bose et al. 2008). The phosphaplatins are also significantly less toxic compared with cisplatin. When administered via an i.v. infusion, the maximum tolerated dose of one phosphaplatin, $((1 R, 2 R$-diaminocyclohexane) dihydrogen-pyrophosphateplatinum(II)), was at least sixfold higher than cisplatin (Moghaddas et al. 2012).

\section{Phenanthriplatin}

Phenanthriplatin, under preclinical development by Blend Therapeutics (USA), is based on the structure of cisplatin where one chloride ligand of cisplatin has been replaced with phenanthridine (Fig. 2). As the drug has only one labile ligand, it is only capable of forming monofunctional adducts with DNA. As a result, the drug distorts the DNA structure to a much lower extent compared with cisplatin, but despite this, is still effective in inhibiting DNA transcript by blocking the action of RNA polymerase II (Kellinger et al. 2013). Phenanthriplatin has both higher cellular uptake compared with cisplatin and is up to 40 -fold more cytotoxic, as determined with an in vitro panel of 60 National Cancer Institute human cancer cell lines (Johnstone et al. 2014, Park et al. 2012).

\section{Macrocycle drug delivery}

Drug delivery for platins is specifically focused on solving either of two problems, i) rapid protein binding in blood serum and intracellular degradation by glutathione, or ii) the drugs' poor selectivity for cancerous tissue over normal tissue. The problem of protein binding and peptidemediated degradation can in part be solved through the encapsulation of the platin drugs within macrocycles. A macrocycle is a short polymer that has ring-closed during synthesis to form a single loop structure. Macrocycles usually contain a hydrophobic cavity that can be accessed through one or more portals. The encapsulation of drugs in the cavity is controlled through hydrophobic effects as well as hydrogen bonds and/or ion-dipole bonds at the portals.

There are three main families of macrocycles relevant to the delivery of platin-based drugs. These include cucurbit $[n]$ urils, $n$-cyclodextrins and calix[n]arenes, where $n$ indicates the number of subunits that make up the macrocycles (Fig. 3).

\section{Cucurbit[n]urils}

Cucurbit $[n]$ urils, abbreviated as $\mathrm{CB}[n]$, are the most studied family of macrocycles with platin-based drugs. The macrocycles are made by reacting glycoluril with formaldehyde in concentrated acid solutions (Assaf \& Nau 2014). The product is a mixture of different sized cucurbit $[n]$ urils with between five and 14 subunits. While not highly soluble in pure water, they become soluble upon forming host-guest complexes with drugs and in solutions with high salt concentrations, such as blood serum, and gastric and nasal fluids (Walker et al. 2011). Cucurbit[n] urils are relatively non-toxic (Oun et al. 2014) and to date have been formulated into oral tablets, topical creams and eye drop solutions (Walker et al. 2010, Chu et al. 2014, Seif et al. 2014). For drug delivery the homologues of six, seven and eight subunits are of most importance as these have a cavity that is ideally sized to store and release platins.

In total, more than 15 platin-based compounds have been examined with cucurbit $[n]$ urils, including the clinical important drugs cisplatin, oxaliplatin and triplatin (Wheate 2008). Cisplatin binds into the cavity of $\mathrm{CB}[7]$ so that the chloride ligands project into the cavity of the macrocycle. Such binding is stabilised by multiple hydrogen-bonds from the drug's ammine hydrogens to
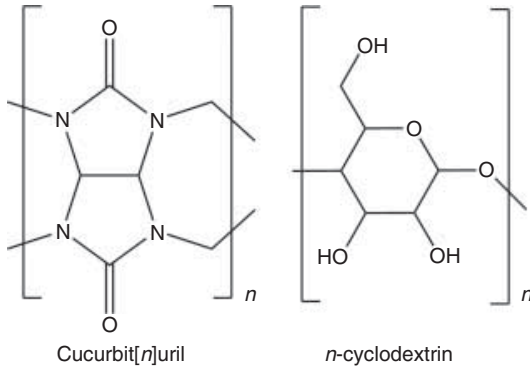

n-cyclodextrin

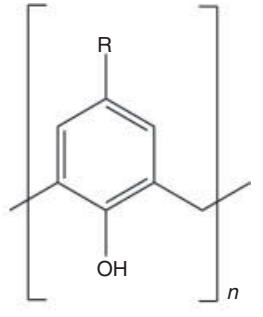

Calix[n]arene
Figure 3

The basic chemical structures of the unfunctionalised macrocycle families that have shown potential as drug delivery vehicles for platins. The $n$ denotes the number of subunits that make up the macrocycles; six to eight for cucurbiturils and cyclodextrins and four for $p$-sulfonatocalixarene. For calix[n]arenes, $\mathrm{R}$ can be a variety of groups, but for drug delivery it is typically an anionic $\mathrm{SO}_{3}$ group.

Published by Bioscientifica Ltd. 
the CB[7]'s oxygens at its portals (Plumb et al. 2012). Binding in this way greatly reduces cisplatin's rate of reaction with proteins and peptides and in vivo makes the drug statistically more effective in treating tumour xenografts, including xenografts resistant to cisplatin (Plumb et al. 2012).

Oxaliplatin forms host-guest complexes with CB[7] in such a way that the hydrophobic diaminocyclohexane ring is located within the macrocycle with the labile oxalate ligand protruding from one portal. The result is a much more stable formulation of the drug in both the solid and solution states, and which is 15 -fold less reactive with methionine compared with normal oxaliplatin (Jeon et al. 2005).

The use of cucurbit $[n]$ urils as protective agents has also been explored for the multinuclear platinum drug triplatin. This drug has three platinum atoms joined via two diaminoalkane ligands. When encapsulated by cucurbit $[n]$ urils, they form a 2:1 $\mathrm{CB}[n]$-to-drug host-guest complex, where the macrocycles are located over the bridging ligands. Importantly, the cytotoxicity and toxicity of triplatin can be tuned by varying the size of the cucurbit[n]uril used (Wheate 2008). Similar to cisplatin and oxaliplatin, encapsulation of triplatin and other multinuclear platins by cucurbit[ $n]$ urils significantly reduces their reactivity, particularly with thiol-containing peptides (Bali et al. 2006, Zhao et al. 2009, Goldoni et al. 2010).

\section{n-Cyclodextrins}

Cyclodextrins are a family of oligosaccharide macrocycles approved for use in pharmaceutical dosage formulations (Rowe et al. 2012). Examples of medicines that include $n$-cyclodextrins as delivery vehicles include Bridion, Zeldox IM and Movectro. While cyclodextrins come in sizes of up to ten subunits, it is the homologues that contain six, seven or eight subunits, designated $\alpha$-, $\beta$ - and $\gamma$-cyclodextrin, respectively, that are used most widely in drug delivery (Davis \& Brewster 2004). All are soluble in water, although $\beta$-cyclodextrin is nephrotoxic and is not used in i.v. formulations. Every $n$-cyclodextrin contains a central cavity that is accessible through two portals. Unlike cucurbit $[n]$ urils, the portals of cyclodextrins are not symmetrical; they contain one major portal and one minor portal. One favourable characteristic of $n$-cyclodextrins, is the ease with which they can be functionalised. Groups to change their lipophilicity/hydrophilicity, or cancer targeting groups, are easily attached using standard chemical techniques.
A number of $n$-cyclodextrin host-guest complexes have been reported with platin compounds (Prashar et al. 2011, Zhao et al. 2014), although only one studied the ability of the macrocycle to slow platin drug degradation (Krause-Heuer et al. 2008). The partial encapsulation of three different platin agents by a carboxylated form of $\beta$-cyclodextrin slowed their degradation by glutathione by at least threefold.

\section{Calix[n]arenas}

Calix $[n]$ arenes are a family of truncated bowl shaped macrocycles of para-substituted phenol monomers linked by methylene bridges. The hydrophobic cavity is accessible through only one portal as the bottom of the macrocycle is closed off by extensive hydrogen bonding between the phenol hydroxide groups. Native calix $[n]$ arenes are soluble only in organic solvents with only one water soluble derivative known; $p$-sulfonatocalix[ $n]$ arenes, where $n=4-8$ (Guo \& Liu 2014). An additional benefit of the negative charges of the sulfate groups, beyond making the macrocycle water soluble, is that they help to form host-guest complexes with positively charged drugs. $p$-sulfonatocalix $[n]$ arenes are relatively non-toxic and have shown considerable potential in drug delivery (Coleman et al. 2008).

There are only a few studies into the application of calix $[n]$ arenes as delivery vehicles for platin drugs. One study directly attached the active component of cisplatin to a carboxylate functionalised calix $[n]$ arene (Pur \& Dilmaghani 2014), whilst all other studies have examined the host-guest formation of platins with p-sulfonatocalix[4]arene.

The nature of the host-guest complexes formed with calix $[n]$ arenes are dependent of the type of platin agent used. For mononuclear complexes a unique 2:2 complex is formed, where two platin molecules stack on top of each other and where each of their ends are covered by a calixarene molecule. The result is a supramolecular complex that resembles a molecular medicine capsule that is highly efficient at preventing drug degradation by glutathione (Krause-Heuer et al. 2008).

In contrast, dinuclear platinum agents form 1:1 hostguest complexes where the bridging ligand is located within the cavity of the calixarene and the platinum groups are located at the portal where they form iondipole and hydrogen bonds with the sulfate groups (Wheate et al. 2009, Brown et al. 2012). In this configuration, the calix $[n]$ arene provides no steric protection for dinuclear platins from glutathione attack and, as such, is

Published by Bioscientifica Ltd. 
not useful for slowing drug degradation. Calix $[n]$ arenes therefore are most suitable for mononuclear platin drugs, like oxaliplatin.

\section{Passive drug targeting}

As discussed, other than drug sequestration and degradation by proteins and peptides, the second major problem of platins is their poor selectivity for cancerous tissue compared with normal tissue. One solution to this problem is the development of nanoparticle formulations. Such formulations are able to better target cancerous tissue due to the enhanced permeability and retention (EPR) effect. The EPR effect is a function of the rapid growth of solid cancers where they develop large gaps between the endothelial cells, which trap and retain nanoparticles; these gaps are not present in normal tissue (Fang et al. 2011, Torchilin 2011). There are a variety of scaffolds that can be utilised as nanoparticle delivery vehicles for platins, including micelles and liposomes, some polymers, metallic nanoparticles and carbon nanotubes.

\section{Micelle and liposome formulation}

One of the most successful methods of nanoparticle formulation for chemotherapeutic drug delivery are micelles and liposomes. Examples of successful drugs using liposomal formulations are doxorubicin (Doxil) and vincristine (VincaXome).

Aroplatin and SPI-77 are liposomal formulations of platin drugs that underwent clinical trials but did not receive subsequent marketing approval for human use. While the development of Aroplatin was stopped for purely economic reasons, SPI-77 failed clinical trials due to a lack of efficacy in phase II patients. The reason for the lack of effectiveness was determined to be the slow and inefficient release of cisplatin from the liposome (Wheate et al. 2010).

\section{LiPlaCis}

The failure of SPI-77 led to the design of liposomal formulations of platin drugs being developed by Liplasome Pharma, where the release of the drug could be triggered through intracellular mechanisms. One example is LiPlaCis a liposomal formulation of cisplatin encapsulated in pro-anticancer ether lipids. This liposome is designed to release cisplatin inside cancer cells upon its degradation by the secretory phospholipase A2 ( $\left.\mathrm{sLA}_{2}\right)$ enzyme (Jensen et al. 2004). This enzyme is overexpressed in many different types of cancers and therefore provides some specificity for tumour tissue over normal tissue. A similar formulation that contains oxaliplatin instead of cisplatin is called LiPloxa.

LiPlaCis has undergone only one clinical trial. In the study, the drug was given as an i.v. infusion over one hour, every three weeks in advanced breast cancer patients (de Jonge et al. 2010). Unfortunately, the study ended early as the results demonstrated no benefit in the dose or toxicity profile when compared with normal cisplatin. The study concluded that LaPlaCis needed reformulation if it was to be effective (de Jonge et al. 2010).

Despite this, the clinical trials database of the U.S. National Institutes of Health (NIH) lists a current phase I trial for LaPlaCis, which was last updated in March 2015. This study is also a dose-escalating safety/efficacy study in patients that preferably have advanced breast cancer. The study is due to be completed in June 2016 .

\section{Lipoplatin}

Lipoplatin is a liposomal formulation of cisplatin under development by Regulon AE. Compared with cisplatin it has higher uptake into tumours in vivo and has significantly fewer and less severe side effects. It has previously undergone numerous clinical trials, including two phase III studies looking at its efficacy in the treatment of squamous cell carcinoma of the head and neck, and for non-small cell lung cancer (Stathopoulos \& Boulikas 2012).

Three current phase III studies are currently listed as ongoing in the European Clinical Trials database. The first is a study in combination with paclitaxel for the first-line treatment of advanced ovarian cancer. The other two studies are in combination with gemcitabine for the firstline treatment of inoperable and either locally advanced or metastatic pancreatic cancer. The ovarian cancer study started in 2006 but no peer-reviewed results have been reported for this trial. One of the pancreatic studies (LipoGEM-PII-1L-Pancr) started in 2012 but appears to be a continuation of an earlier pancreatic study started in 2009.

\section{Polymers}

Polymer-based nanoparticles for the delivery of platin drugs can come in a variety of forms from polydispersed linear polymers that roughly roll up into a nanoparticle shape, to the high ordered and monodispersed polymers called dendrimers.

Published by Bioscientifica Ltd. 


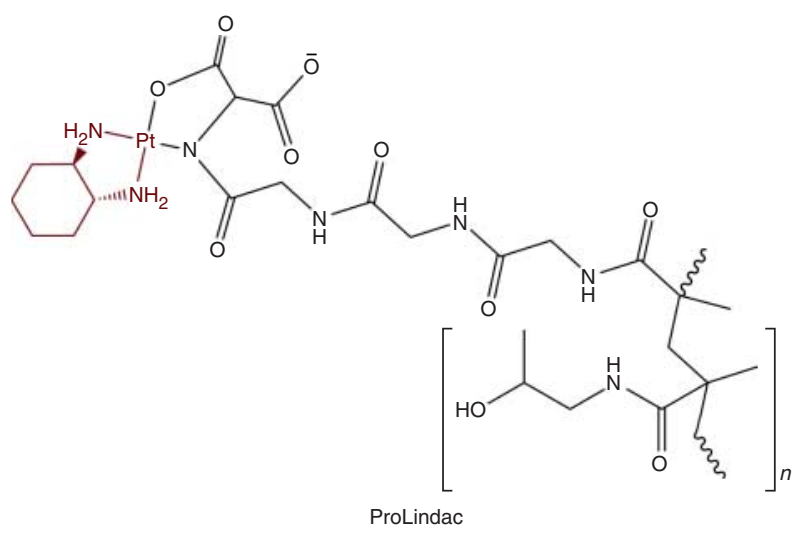

Figure 4

The structure of the platin polymer formulation, ProLindac, that yields the same active component as oxaliplatin (shown in red) in the low $\mathrm{pH}$ environment of cancer cells.

\section{ProLindac}

ProLindac is a polymer formulation of platin that yields the same active component as oxaliplatin inside of cancer cells (Fig. 4). It's made from the highly hydrophilic and biocompatible polymer hydroxypropylmethacrylamide. Attachment of the platin to the polymer is stable at blood serum $\mathrm{pH}$, but upon entering the lower $\mathrm{pH}$ environment of a cancer cell the platin drug is slowly aquated and goes on to bind DNA. ProLindac has undergone a number of phase I and II trials and while it is no longer listed as a drug under development by Abeona Therapeutics (formerly Access Pharmaceuticals) an ongoing phase III clinical trial for the treatment of head and neck cancers remains listed on the NIH clinical trials database.

\section{Dendrimers}

Dendrimers are highly branched synthetic polymers that are made using a step-by-step reaction and are highly useful in drug delivery (Rolland et al. 2009, Tekade et al. 2009). They can be synthesised in a variety of sizes, often referred to as generations, which represent the number of branching points in the polymer from the central core (Tekade et al. 2009). They are able to bind drugs in a variety of ways, including electrostatic interactions, pocket binding and chemical tethering to the dendrimer surface.

For platins the most studied and useful are the polyamidoamine (PAMAM) dendrimers. Full generation PAMAM dendrimers have amine surface groups that can be used to irreversibly bind platinum, thus using the dendrimer as part of the structure of the drug rather than as a delivery vehicle (Kapp et al. 2010). Half-generation PAMAM dendrimers have carboxylate surface groups and can bind cationic platin drugs via electrostatic interactions (Pisani et al. 2009). Alternatively, the carboxylate groups on the surface of dendrimers can be used to tether the platins. Upon aquation inside cancer cells, the dendrimer releases the active component of cisplatin or oxaliplatin (Haxton \& Burt 2008, Kirkpatrick et al. 2011, Nguyen et al. 2015).

The major problem of dendrimers as nanoparticle delivery vehicles for platins is the potential irreversible binding of drugs to the branches of the polymer. This can occur where there are accessible amine groups which are common in PAMAM dendrimers (Kirkpatrick et al. 2011). Such binding, which increases over time, can make it difficult to predict the releasable dose of drug and hence could result in ineffective patient treatment. To overcome this, dendrimers without amine groups within the branches have been synthesised. Two examples are ester and thiol-based dendrimers with terminal hydroxyl or carboxylate groups that can be used as drug delivery vehicles (Chen et al. 2009).

\section{Proteins}

A major protein found in blood serum, which can potentially act as a delivery vehicle for platins, is transferrin. This protein is useful as a delivery vehicle because many cancer types overexpress transferrin receptors on their cell surfaces. Tranferrin is responsible for transporting iron around the body and has two high affinity $\mathrm{Fe}^{3+}$ sites. When the protein is bound to two iron atoms it is called holo-transferrin and when not bound by iron is called apo-transferrin. Drug delivery studies of cisplatin have been undertaken with both forms of the protein.

Cisplatin can bind to the hydroxyl group of the threonine 457 residue, which is located in the iron binding pocket (Khalaila et al. 2005), although other binding sites are thought to exist. As such, cisplatin binds the protein competitively with iron, and a higher loading of cisplatin is achieved with apo-transferrin (22 cisplatin molecules per protein) compared with holo-transferrin (15 cisplatin molecules per protein) (Hoshino et al. 1995, Luo et al. 2012).

It appears, however, that cisplatin binding to transferrin affects the shape of transferrin as there is a correlation between the number of bound cisplatin molecules and the ability of transferrin to bind to its cellular receptor. As the number of drug molecules

Published by Bioscientifica Ltd 
increases from three to seven the binding strength to the protein receptor drops, and with 15 attached cisplatin molecules, transferrin loses all binding potential with the receptor (Hoshino et al. 1995).

\section{Metal nanoparticles}

Nanoparticles made from metals, such as gold, platinum or iron oxide, can be produced in a variety of shapes, including spheres, rods and pyramids, and bowls. All of these have shown potential as drug delivery vehicles and in other medical applications such as diagnostics and photothermal therapy (Dykman \& Khlebtsov 2012). Gold and iron oxide nanoparticles have both been examined as delivery vehicles for platin drugs.

While platin drugs have been loaded onto the surface of gold nanoparticles directly (Sanchez-Paradinas et al. 2014), this binding is weak and likely results in the considerable loss of drug upon entering the high salt environment of blood serum. Instead, platin drugs are usually tethered to the nanoparticle surface using thiolbased chemical linkers. On solid gold nanoparticles thiols are known to bind strongly to the surface and in the process form monolayers. The use of dithiols in the linker can further strengthen the bond of the tether to the nanoparticles (Craig et al. 2012). Use of a carboxylate functional group on the other end of the tether facilitates attachment of a platin drug (Brown et al. 2010). Alternatively, a unique tethering method has been devised where a thiol-modified cyclodextrin is attached to the surface of the gold nanoparticle (Fig. 5). The platin drug is

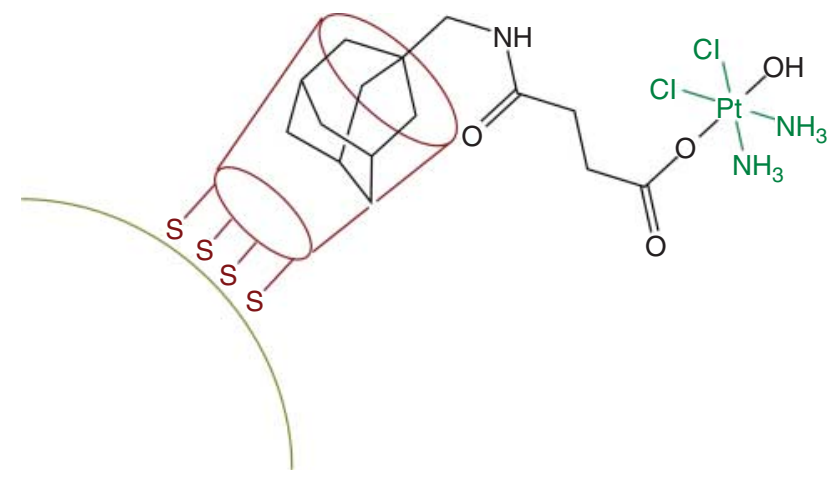

Figure 5

A schematic diagram showing a unique method of attaching a platin drug to the surface of gold nanoparticles. Cyclodextrin macrocycles (red), which have been modified with thiol-groups on the minor portal, form a monolayer on the surface of the gold (yellow). The platin drug is held to the cyclodextrin through an adamantine ligand (black). Upon entering the cells, the platin is reduced from platinum(IV) to platinum(II), thus releasing cisplatin (green). modified with an adamantine ligand, which forms a hostguest complex with the cyclodextrin by binding within its cavity (Shi et al. 2013).

Iron oxide nanoparticles are also of particular interest for use in platin drug delivery. As iron remains susceptible to magnetic fields in its oxidised state, such nanoparticles can be actively transported to solid cancers in the body using external magnetic fields (Wagstaff et al. 2012). While the iron oxide nanoparticle may be reactive in the human body and break down, it can be pacified by the addition of a gold coating. Such a coating does not affect the magnetic properties of the iron oxide (Wagstaff et al. 2012).

Gold- and gold-plated nanoparticles do have some disadvantages as delivery vehicles (Craig et al. 2012). First it can be difficult to control accurately the size of the nanoparticles. Many of the methods used to synthesise the nanoparticles result in a bell distribution of particles that can vary in size significantly. Another problem is the scale on which the nanoparticles can be synthesized; typically in the nanomolar, and at best micromolar, concentration ranges. Stability of the nanoparticles can also be a problem. Gold nanoparticles can agglomerate in solution, which has two effects: a growth in the size of the nanoparticles and reduced suspension stability. Finally, the loading of platin drug onto the nanoparticles can vary, with batch-to-batch variability of loading of up to $30 \%$.

\section{Carbon nanotubes}

Carbon nanotubes are an allotrope of carbon and are long, cylinder-like molecules. Carbon nanotubes are passively selective for cancer cells due to their size; they can have lengths between 10 and $1000 \mathrm{~nm}$. How they are taken up by cells is not completely understood and is thought to comprise a mixture of endocytosis and needle-like entry (Fabbro et al. 2012).

Carbon nanotubes can deliver platin drugs in three different ways: i) the drug can be stored within the cavity of the nanotube, ii) the drug can be directly attached to the surface of the nanotubes that have been functionalised with carboxylic acid or amine groups, or iii) the drug can be attached through the use of a chemical tether (Fig. 6).

In open-ended carbon nanotubes, platin drugs can be loaded into the cavity of the tubes through simple diffusion (Fig. 6A). If carbon nanohorns are used (carbon nanotubes with rounded ends that cap the particles), then holes can be created in the tubes by heating them up to $500{ }^{\circ} \mathrm{C}$ before the drug is loaded (Ajima et al. 2006). Release of platins from the nanotubes is controlled either through diffusion or through the use of iron nanoparticle caps

Published by Bioscientifica Ltd. 


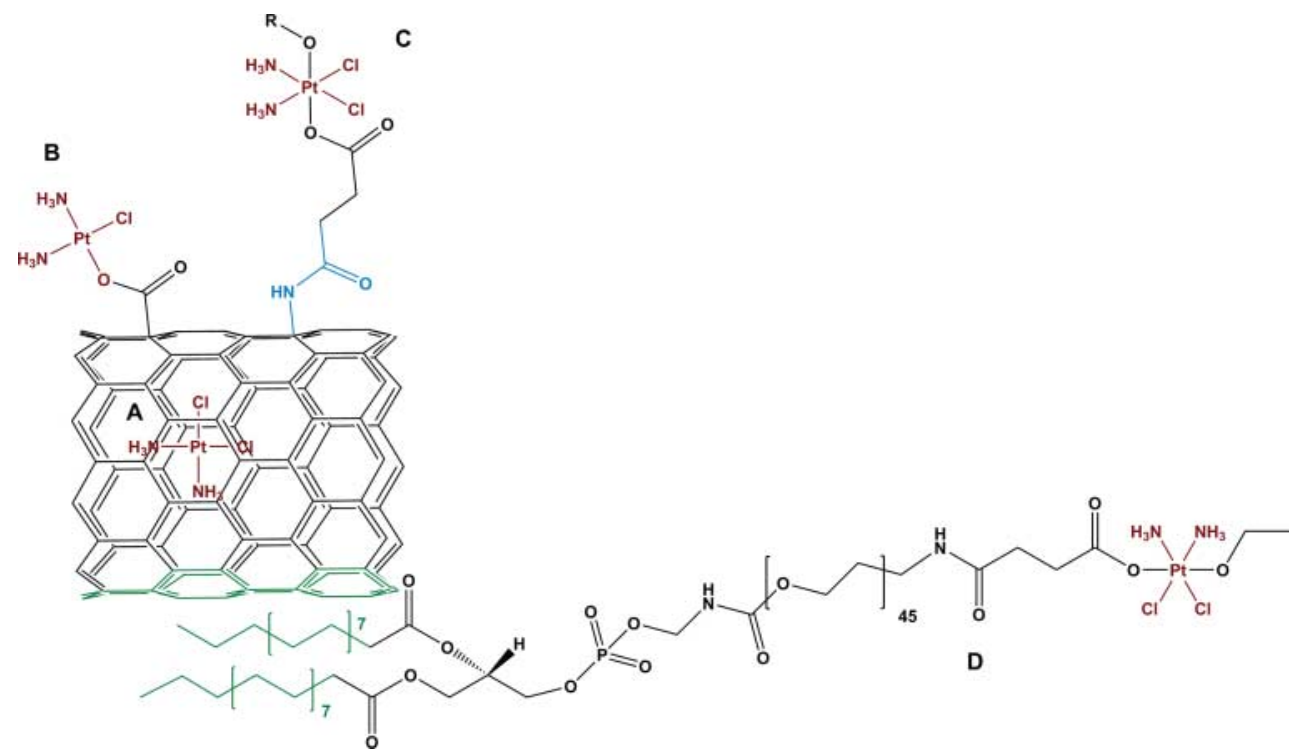

\section{Figure 6}

The four methods of attachment of platin drugs (red) to carbon nanotubes showing (A) cisplatin encapsulation within the cavity, (B) coordination to surface carboxylate groups, (C) coordination to

(Panczyk et al. 2013). Modelling has shown that a variety of platins can be encapsulated inside the cavity of nanotubes, including cisplatin, nedaplatin, carboplatin and oxaliplatin (Mahdavifar \& Moridzadeh 2014). Whilst either single or multi-walled carbon nanotubes can be used (Li et al. 2014), the radius of the tubes does affect both the loading and release characteristics of the platins (Mejri et al. 2015). A minimum radius of $4.8 \AA$ is needed to accommodate cisplatin, with $5 \AA$ the ideal radius (Hilder \& Hill 2007).

Alternatively, platins can be directly attached to the surface of functionalised carbon nanotubes. Where the tubes have been synthesised with surface carboxylate groups (Fig. 6B), attachment of the platin drugs can be surface amine groups through the formation of a peptide bond (blue) and (D) through a tether that holds the platin to the surface of the carbon nanotube through hydrophobic effects (green).

achieved through direct coordination (Bhirde et al. 2009). In this case, release of the drug is dependent on aquation inside of cancer cells. If the carbon nanotubes have been functionalised with amine surface groups, then a platinu$\mathrm{m}(\mathrm{IV})$ drug with carboxylate ligands can be attached through the formation of an amide bond (Fig. 6C). Drug release is then achieved when the platin is reduced from platinum(IV) to platinum(II) inside the cancer cell (Dhar et al. 2008a,b).

Finally, platin drugs can be attached to carbon nanotubes through the use of a tether (Fig. 6D) held to the surface of the tubes through hydrophobic effects (Feazell et al. 2007). Similar to the amide attached platin

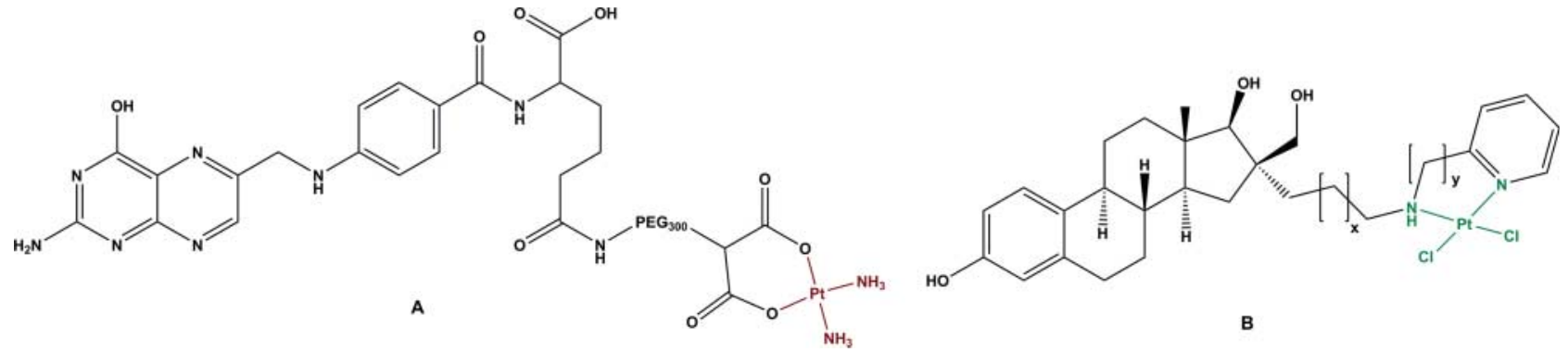

Figure 7

Examples of two complexes where a platin drug has been coordinated to an essential nutrient to increase the selectivity of the platinum for cancer cells showing (A) the active component of cisplatin (red) attached to folic acid and (B) the use of chemically modified estradiol to permanently incorporate a cisplatin-like drug (green) into its structure, where $x=2,4,6$ or 8 and $y=1$ or 2 . 
(C) described above, the drug is released within cancer cells when it is reduced to platinum(II).

There are some safety problems with carbon nanotubes, however, that could make them unsuitable as delivery vehicles for platins. For example, because they are so small, carbon nanotubes can become easily airborne and be breathed in by health staff and patients (Pulskamp et al. 2007). In the lung, they can then potentially act in the same manner as asbestos, given their similar size and needle-like shape, causing inflammation and lesions that can then develop into mesothelioma; a cancer of the lining of the lungs (Poland et al. 2008).

\section{Active drug targeting}

An alternative method to passive targeting of platin drugs to cancerous tissues is the use of active targeting agents. These agents selectively recognise and bind to proteins and peptides on the surface of cancer cells. Some receptors can be for essential nutrients needed for the growth of the cancer. In these instances, the receptors are overexpressed on cells, but are not specific for cancer cells and thus provide pseudo-active targeting. For other receptors, these may be unique to individual cancer cells, and thus, their targeting provides a very selective method of drug delivery.

\section{Substrates and nutrients}

Platins have been tethered to a range of substrates and nutrients, including vitamins, steroids, amino acids and sugars. Folic acid is a vitamin used by cells to synthesise nucleobases for the production of DNA, and hence, is essential for cell proliferation. Many cancerous cells overexpress folate receptors on their surface to ensure a high supply of folic acid. Therefore, folate can be used as a pseudoselective targeting agent for many different types of cancers (Xia \& Low 2010). Folic acid contains two carboxylic acid groups that can be directly coordinated to the active components of cisplatin and oxaliplatin (for an example, Fig. 7A). Alternatively, cisplatin has been conjugated to folic acid through the use of a PEG spacer (Aronov et al. 2003). In either case, aquation of the drug inside the cell yields the active component of cisplatin. Folate has also been attached to the surface of different delivery vehicles, like carbon nanotubes and micelles, for the delivery of platins (Dhar et al. 2008a,b, Eliezar et al. 2015).

Estrogens are a family of hormones of particular importance in the treatment of several types of cancer. Estrogen receptors are highly expressed in breast (60$70 \%)$, uterus (70-73\%) and ovarian (60\%) cancers, and as such, provide another pseudo-selective target for platin drugs (Gagnon et al. 2004). Of particular interest for platin drug delivery is $17 \beta$-estradiol. There are no suitable functional groups on estradiol for the direct attachment of a platin drug and so it has been chemically modified to provide accessible amine groups (Fig. 7B) (Descoteaux et al. 2003). As the platin is coordinated via amine ligands, the estradiol is not removed during aquation and thus remains a permanent part of the drug upon its binding to DNA (Gagnon et al. 2004).

\section{Antibodies and peptides}

While nutrients can give platins some selectivity for cancerous cells over normal cells, but may not result in improved effectiveness if the nutrient-drug complex is unable to penetrate into the cell after receptor binding. Higher selectivity for cancer cells can be achieved using antibodies and short peptides, especially cell penetrating peptides.

A recent study has successfully conjugated a cisplatinlike platin to the monoclonal antibody-based drug trastuzumab, which recognises and binds HER2 receptors that may be present on breast cancers (Waalboer et al. 2015). By varying the linker used to tether the platin to the antibody, it was found that 2-3 drug molecules could be attached but that this affected the stability of the antibody-drug complex. Importantly, tethering of platinum to the antibody did not affect the immunoreactivity of the antibody.

A range of different peptides have been discovered that can be used to improve drug uptake into cells. The 12 residue peptide (TMGFTAPRFPHY), called PH1, is selective for the tyrosine kinase-based Tie2 receptor that is overexpressed on a number of different cancer cell lines. It has been tethered to the surface of cisplatin containing liposomes to improve the drug's selectivity for cancerous tissue (Mai et al. 2009).

Integrin receptors can be targeted by peptides that contain Arg-Gly-Asp (RGD) sequences in their structure. A platinum(IV) derivative of picoplatin has been tethered to cyclic and RAFT versions of RGD (Massaguer et al. 2015). An 11 residue fragment of the TAT protein (YGRKKRRQRRR), derived from HIV-1, is useful for carrying drugs across cell membranes. A platinum(IV) derivative of oxaliplatin has been tethered to a TATfragment using solid-phase chemistry. Either one or two platins can be tethered to a single peptide and both are more active in cancer cells compared with oxaliplatin complexes without the peptide (Abramkin et al. 2012).

Published by Bioscientifica Ltd 
Unfortunately, the tethering of platins to antibodies and peptides is synthetically non-trivial. There are many amino acid functional groups within antibodies to which the platins can attach. For instance, they can reversibly bind to aspartic acid and glutamate residues via their carboxylate groups and irreversibly bind to any amino acid residue that contains accessible amine groups, e.g. arginine, histidine, lysine and tryptophan. Sulphurcontaining amino acids, such as methionine and cysteine also provide a target for platins. Regardless of which amino acids become bound by platins the act of platin binding can ultimately affect the antibodies' and peptides' shapes and receptor binding properties, so other means for synthesizing antibody- and peptide-platin vehicles are needed.

\section{Aptamers}

Aptamers are short (usually 20-100 bases) DNA or RNA strands that bind proteins and peptides with high target selectivity. They are generated through the process of systematic evolution of ligands by exponential enrichment. In many ways aptamers can be superior to antibodies as they are just as selective and have identical binding affinities but are also non-immunogenic, more easily synthesized and can be generated against practically any target. In cancer, aptamers can be used in a variety of ways, including cancer diagnostics and testing, as a therapeutic agent for cancer and as active targeting agents for drug delivery (Lao et al. 2015, Ma et al. 2015).

Aptamers have been used as active targeting agents for a number for platin-based drugs. Cisplatin has been encapsulated into liposomes to which the AS1411 aptamer was tethered to the surface (Cao et al. 2009). This aptamer is specific for nucleolin, which is a cell proliferation protein overexpressed on the surface of many types of cancer cells. The conjugation of cholesterol to the end of the aptamer facilitated attachment to the surface of the liposome when it was absorbed into the lipid bilayer.

A platinum(IV) complex, similar to LA-12, which yields cisplatin when reduced inside the cell, has also been included in liposomes that are actively targeted to prostate cancer cells via the attachment of the prostate specific membrane antigen selective aptamer called A10 (Dhar et al. $2008 a, b)$. For this delivery system, the aptamer is attached to the surface of the liposome through an amide bond between the carboxylate groups on the liposome surface and an amine attached to the $3^{\prime}$ end of the aptamer.

While both liposome-aptamer delivery systems demonstrated improved in vitro cytotoxicity and uptake compared with the free drugs, neither system was tested with in vivo models. As such, both may display the same inherent drug release problems observed with SPI-77 (see section on liposome delivery of platin drugs). As such, there has been recent interest in finding ways of dispensing with the delivery vehicle entirely and using aptamers as both the active cancer targeting agent and as the drug delivery vehicle. Such a method is called apticular drug delivery, which is a contraction and combination of the words aptamer and vehicular.

Normal platin drugs that form coordination binds with guanosine and adenosine residues with DNA are unsuitable for use as they may irreversibly bind to the aptamer instead of their target, nuclear DNA. Inert platin compounds, such as phenanthroline-based platins (Wheate et al. 2007), can be used as potential drugs (Davis et al. 2012). These agents, are capable of reversibly intercalating between the base-pairs in double stranded DNA structures such as those available in many aptamers (Kemp et al. 2007).

In solution, many aptamers will fold to form regions of double helical DNA. One such aptamer is sgc8c, which is selective for T cell leukaemias (Shangguan et al. 2007). This aptamer forms a loop and stem structure into which the platin complex, PHENEN, was intercalated for simultaneous targeting and drug delivery. Unfortunately, intercalation of the platin into the aptamer locked the stem and loop conformation and resulted in a decrease in both the in vitro cytotoxicity and uptake of the platin compared with its free form (McGinely et al. 2013).

Therefore, if aptamers are to be used as delivery vehicles, a mechanism by which platin drugs can be loaded into the aptamers needs to be developed that does not affect the aptamer's secondary or tertiary conformation and its ability to recognise its cellular target.

\section{Functional genomics for predicting patient response to platins}

The third big challenge for platin drugs is inter-patient variability in response to platin treatment. This includes patient-to-patient changes in drug pharmacokinetics and tumour response, and the severity of the side effects. Recent research has shown that it may be possible to use genetics to predict tumour response and side effects, and this could become a standard diagnostic tool in the selection of both the drug to be used and the most appropriate dose for administration.

Published by Bioscientifica Ltd 


\section{Predicting toxic side effects}

A number of different side effects caused by platin drugs have been examined to see if genetic variations can predict their level of severity. Ototoxicity has been significantly studied, mainly as this is a side effect mostly associated with platin therapy and due to the number of patients that experience this toxicity: $70 \%$ of children require a hearing aid after prolonged treatment with a platin drug (Xu et al. 2015).

Several studies have identified potential gene variants that appear to predict severe ototoxicity. One study has identified the variant $r s 1872328$ of the ACYP2 gene as one such marker, which codes for an enzyme that has an effect on $\mathrm{Ca}^{2+}$ homeostasis in muscles and the cochlea (Xu et al. 2015). Patients that were positive for the variant were found to be predisposed to severe ototoxicity from cisplatin.

\section{Predicting drug efficacy}

Cisplatin is used to treat squamous cell carcinomas of the head and neck. For these types of cancers, TP53 is the most varied gene, with between 60 and $80 \%$ having a mutation. In one study that used an evolutionary action score to assess the mutations, it was found that a subset of high-risk TP53 mutations demonstrated significantly reduced in vitro and in vivo drug efficacy, making the gene a potential prognostic marker for selection of cisplatin in treatment of head and neck cancers (Osman et al. 2015).

In another study, the predictive efficacy of cisplatin and carboplatin was examined in triple negative breast cancer. Whilst platins are not normally a first-line treatment for breast cancer, one phase II clinical study has found that patients that do not have mutations of $B R C A 1$ and BRCA2, which results in lower DNA double strand break repairs, may be a predictive tool for the selection of platins for treatment (Isakoff et al. 2015).

In some instances, both toxicity and efficacy can be predicted together. One study found that the leukopenia side effect and efficacy of cisplatin can be predicted in part by testing the level of DNA binding by the drug in peripheral blood leukocytes in children (Veal et al. 2001). The level of DNA binding in those cells was found to be a related to patient-specific factors and not a simple function of cisplatin pharmacokinetics. The study concluded that testing patients' blood samples before treatment can be used to predict both the level of expected leukopenia and the expected effectiveness of the drug.
Overall, the application of functional genomics will have the biggest and fastest impact on platin-based chemotherapy in the coming decade. The studies completed so far just scratch the surface and it is likely that many more markers will be found to predict the severity of other toxicities and drug effectiveness in many more cancer types.

\section{Conclusions}

Platin drugs remain one of the most important and used families of chemotherapy drugs and are not likely to be replaced clinically any time soon. They are not without their drawbacks, with severe side effects limiting the dose that can be given to patients and the development of drug resistance by many types of cancers. While new platin drugs continue to be developed, they are likely to suffer from the same problems, and as such, there is now considerable focus on developing new formulations that are more stable and more selective for cancers. No one formulation method perfectly solves the problems of platin drugs, and many introduce their own problems, such as inherent toxicity, poor or uncontrolled drug release, variability in drug loading or changes in particle drug delivery size and stability. Importantly, active targeting agents that include nutrients, proteins, antibodies and aptamers are beginning to show promise, although the mechanism of drug attachment and release still needs to be resolved in some cases. Finally, the use of functional genomics is beginning to show promise in delivering platin drugs as personalised medicines, allowing doctors to select agents based on both their expected efficacy to individual patients and the likelihood of severe side effects. Markers for predicting ototoxicity and for drug activity for head and neck cancers have already been found, and many more are likely waiting to be uncovered.

Declaration of interest

$\mathrm{N} J$ Wheate is a named inventor on two patents for macrocycle and nanoparticle delivery vehicles for platin drugs.

\section{Funding}

This research did not receive any specific grant from any funding agency in the public, commercial or not-for-profit sector.

\section{Author contribution statement}

M G Apps and E H Y Choi conducted literature searches and proof read the manuscript. N J Wheate conducted literature searches, collated information, and prepared and proof read the manuscript.

Published by Bioscientifica Ltd. 


\section{References}

Abramkin S, Valiahdi SM, Jakupec MA, Galanski M, Metzler-Nolte N \& Keppler BK 2012 Solid-phase synthesis of oxaliplatin-TAT peptide bioconjugates. Dalton Transactions 41 3001-3005. (doi:10.1039/ c2dt12024k)

Ajima K, Maigne A, Yudasaka M \& Iijima S 2006 Optimum hole-opening condition for cisplatin incorporation in single-wall carbon nanohorns and its release. Journal of Physical Chemistry. B 110 19097-19099. (doi:10.1021/jp064915x)

Aronov O, Horowitz AT, Gabizon A \& Gibson D 2003 Folate-targeted PEG as a potential carrier for carboplatin analogs. Synthesis and in vitro studies. Bioconjugate Chemistry 14 563-574. (doi:10.1021/bc0256421)

Assaf KI \& Nau WM 2014 Cucurbiturils: from synthesis to high-affinity binding catalysis. Chemical Society Reviews 44 394-418. (doi:10.1039/ C4CS00273C)

Bali MS, Buck DP, Coe AJ, Day AI \& Collins JG 2006 Cucurbituril binding of trans-[\{PtCl(NH3)2 $\} 2(\mu-\mathrm{NH} 2(\mathrm{CH} 2) 8 \mathrm{NH} 2)]^{2+}$ and the effect on the reaction with cysteine. Dalton Transactions 5337-5344. (doi:10.1039/ b609881a)

Bhirde AA, Patel V, Gavard J, Zhang G, Sousa AA, Masedunskas A, Leapman RD, Weigert R, Gutkind JS \& Rusling JF 2009 Targeted killing of cancer cells in vivo and in vitro with EGF-directed carbon nanotube-based drug delivery. ACS Nano 3 307-316. (doi:10.1021/nn800551s)

Bose RN, Maurmann L, Mishur RJ, Yasui L, Gupta S, Grayburn WS, Hofstetter H \& Salley T 2008 Non-DNA-binding platinum anticancer agents: cytotoxic activities of platinum-phosphato complexes towards human ovaian cancer cells. PNAS 105 18314-18319. (doi:10.1073/ pnas.0803094105)

Bouchal P, Jarkovsky J, Hrazdilova K, Dvorakova M, Struharova I, Hernychova L, Damborsky J, Sova P \& Vojtesek B 2011 The new platinum-based anticancer agent LA-12 induces retinal binding protein 4 in vivo. Proteome Science 9 1-9. (doi:10.1186/1477-5956-9-68)

Brown SD, Nativo P, Smith J-A, Stirling D, Edwards PR, Venugopal B, Flint DJ, Plumb JA, Graham D \& Wheate NJ 2010 Gold nanoparticles for the improved anticancer drug delivery of the active component of oxaliplatin. Journal of the American Chemical Society 132 4678-4684. (doi:10.1021/ja908117a)

Brown SD, Plumb JA, Johnston BF \& Wheate NJ 2012 Folding of dinuclear platinum anticancer complexes within the cavity of para-sulphonatocalix[4]arene. Inorganica Chimica Acta 393 182-186. (doi:10.1016/j.ica. 2012.04.033)

Cao Z, Tong R, Mishra A, Xu W, Wong GCL, Cheng J \& Lu Y 2009 Reversible cell-specific drug delivery with aptamer-functionalized liposomes. Angewandte Chemie (International ed. in English) 48 6494-6498. (doi:10.1002/anie.200901452)

Chen G, Kumar J, Gregory A \& Stenzel MH 2009 Efficient synthesis of dendrimers via a thiol-yne and esterification process and their potential application in the delivery of platinum anti-cancer drugs. Chemical Communications 41 6291-6293. (doi:10.1039/b910340f)

Chu JJ, Apps MG \& Wheate NJ 2014 Chemical factors affecting cucurbit[n]uril formulation into ocular dosage forms: excipient binding, solubility, corneal permeability and antibiotic encapsulation. Supramolecular Chemistry 26 648-656. (doi:10.1080/10610278.2014. 926361)

Coleman AW, Jebors S, Cecillon S, Perret P, Garin D, Marti-Battle D \& Moulin M 2008 Toxicity and biodistribution of para-sulfonatocalix[4]arene in mice. New Journal of Chemistry 32 780-782. (doi:10.1039/b718962a)

Craig GE, Brown SD, Lamprou D, Graham D \& Wheate NJ 2012 Cisplatin tethered gold nanoparticles which exhibit enhanced reproducibility, drug loading and stability - a step closer to pharmaceutical approval? Inorganic Chemistry 51 3490-3497. (doi:10.1021/ic202197g)
Dasari S \& Tchounwou PB 2014 Cisplatin in cancer therapy: molecular mechanisms of action. European Journal of Pharmacology $\mathbf{7 4 0} 364-378$. (doi:10.1016/j.ejphar.2014.07.025)

Davis ME \& Brewster ME 2004 Cyclodextrin-based pharmaceutics: past, present and future. Nature Reviews. Drug Discovery 3 1023-1035. (doi:10.1038/nrd1576)

Davis KJ, Carrall JA, Lai B, Aldrich-Wright JR, Ralph SF \& Dillon CT 2012 Does cytotoxicity of metallointercaltors correlate with cellular uptake or DNA affinity? Dalton Transactions 41 9417-9426. (doi:10.1039/ c2dt30217a)

Descoteaux C, Provencher-Mandeville J, Mathieu I, Perron V, Mandal SK, Asselin E \& Berube G 2003 Synthesis of $17 \beta$-estradiol platinum(II) complexes: Biological evaluation on breast cancer cell lines. Bioorganic \& Medicinal Chemistry Letters 13 3927-3931. (doi:10.1016/j.bmcl.2003. 09.011)

Dhar S, Gu FX, Langer R, Farokhzad OC \& Lippard SJ 2008a Targeted delivery of cisplatin to prostate cancer cells by aptamer functionalized Pt(IV) prodrug-PLGA-PEG nanoparticles. PNAS 105 17356-17361. (doi:10.1073/pnas.0809154105)

Dhar S, Liu Z, Thomale J, Dai H \& Lippard SJ 2008b Targeted single-walled carbon nanotube-mediated $\mathrm{Pt}(\mathrm{IV})$ prodrug delivery using folate as a homing device. Journal of the American Chemical Society 130 11467-11476. (doi:10.1021/ja803036e)

Dykman L \& Khlebtsov N 2012 Gold nanoparticles in biomedical applications; recent advances and perspectives. Chemical Society Reviews 41 2256-2282. (doi:10.1039/C1CS15166E)

Eliezar J, Scarano W, Boase NRB, Thurecht K \& Stenzel MH 2015 In vivo evaluation of folate decorated cross-linked micelles for the delivery of platinum anticancer drugs. Biomacromolecules 16 515-523. (doi:10.1021/bm501558d)

Fabbro C, Ali-Boucetta H, Da Ros T, Kostarelos K, Bianco A \& Prato M 2012 Targeting carbon nanotubes against cancer. Chemical Communications 48 3911-3926. (doi:10.1039/c2cc17995d)

Fang J, Nakamura H \& Maeda H 2011 The EPR effect: unique features of tumor blood vessels for drug delivery, factors involved, and limitations and augmentation of the effect. Advanced Drug Delivery Reviews 63 136-151. (doi:10.1016/j.addr.2010.04.009)

Feazell RP, Nakayama-Ratchford N, Dai H \& Lippard SJ 2007 Soluble singlewalled carbon nanotubes as longboat delivery systems for platinum(IV) anticancer drug design. Journal of the American Chemical Society 129 8438-8439. (doi:10.1021/ja073231f)

Gagnon V, St-Germain M-E, Descoteaux C, Provencher-Mandeville J, Parent S, Mandal SK, Asselin E \& Berube G 2004 Biological evaluation of novel estrogen-platinum(II) hybrid molecules on uterine and ovarian cancers - molecular modeling studies. Bioorganic \& Medicinal Chemistry 14 5919-5924. (doi:10.1016/j.bmcl.2004.09.015)

Galluzzi L, Senovilla L, Vitale I, Michels J, Martins I, Kepp O, Castdeo M \& Kroemer G 2012 Molecular mechanisms of cisplatin resistance. Oncogene 31 1869-1883. (doi:10.1038/onc.2011.384)

Goldoni L, Grugni M, De Munari S, Cassin M \& Bernardini R 2010 Cucurbit[7]uril inclusion complexes of platinum(II)-based anticancer drugs: further insight. Chemistry Letters 39 676-677. (doi:10.1246/cl. 2010.676)

Guo D-S \& Liu Y 2014 Supramolecular chemistry of $p$-sulfonatocalix[n] arenes and its biological applications. Accounts of Chemical Research $\mathbf{4 7}$ 1925-1934. (doi:10.1021/ar500009g)

Harper BW, Krause-Heuer AM, Grant MP, Manohar M, GarbutcheonSingh KB \& Aldrich-Wright JR 2010 Advances in platinum chemotherapeutics. Chemistry 16 7064-7077. (doi:10.1002/chem.201000148)

Haxton KJ \& Burt HM 2008 Hyperbranched polymers for controlled release of cisplatin. Dalton Transactions 43 5872-5875. (doi:10.1039/b809949a)

Hilder TA \& Hill JM 2007 Modelling the encapsulation of the anticancer drug cisplatin into carbon nanotubes. Nanotechnology 18275704 (275708pp). (doi:10.1088/0957-4484/18/27/275704)

Hoshino T, Misaki M, Yamamoto M, Shimizu H, Ogawa Y \& Toguchi H 1995 Receptor-binding, in vitro cytotoxicity, and in vivo distributions of

Published by Bioscientifica Ltd 
transferrin-bound cis-platinum(II) differing molar ratios,. Journal of Controlled Release 37 75-81. (doi:10.1016/0168-3659(95)00066-H)

Isakoff SJ, Mayer EL, Traina TA, Carey LA, Krag KJ, Rugo HS, Liu MC, Stearns V, Come SE, Timms KM et al. 2015 TBCRC009: a multicenter phase II clinical trial of platnum monotherapy with biomarker assessment in metastatic triple-negative breast cancer. Journal of Clinical Oncology 33 1902-1909. (doi:10.1200/JCO.2014.57.6660)

Jensen SS, Andersen TL, Davidsen J, Hoyrup P, Shnyder SD, Bibby MC, Gill JH \& Jorgensen K 2004 Secretory phospholipase A2 as a tumorspecific trigger for targeted delivery of a novel class of lipsomal prodrug anticancer etherlipids. Molecular Cancer Therapeutics 3 1451-1458.

Jeon YJ, Kim S-Y, Ko YH, Sakamoto S, Yamaguchi K \& Kim K 2005 Novel molecular drug carrier: encapsulation of oxaliplatin in cucurbit[7]uril and its effects on stability and reactivity of the drug. Organic \& Biomolecular Chemistry 3 2122-2125. (doi:10.1039/b504487a)

Johnstone TC, Park GY \& Lippard SJ 2014 Understanding and improving platinum anticancer drugs - phenanthriplatin. Anticancer Research $\mathbf{3 4}$ 471-476.

de Jonge MJA, Slingerland M, Loos WJ, Wiemer EAC, Burger H, Mathijssen RHJ, Kroep JR, den Hollander MAG, van der Biessen D, Lam M-H et al. 2010 Early cessation of the clinical development of LiPlaCis, a liposomal cisplatin formulation. European Journal of Cancer $\mathbf{4 6}$ 3016-3021. (doi:10.1016/j.ejca.2010.07.015)

Kapp T, Dullin A \& Gust R 2010 Platinum(II)-dendrimer conjugates: synthesis and investigations on cytotoxicity, cellular distribution, platinum release, DNA and protein binding. Bioconjugate Chemistry 21 328-337. (doi:10.1021/bc900406m)

Kauffman GB, Pentimalli R, Doldi S \& Hall MD 2010 Michele Peyrone (1813-1883), discoverer of cisplatin. Platinum Metals Review 54 250-256. (doi:10.1595/147106710X534326)

Kellinger MW, Park GY, Chong J, Lippard SJ \& Wang D 2013 Effect of a monofunctional phenanthriplatin-DNA dduct on RNA polymerase II transcription fidelity and translesion synthesis. Journal of the American Chemical Society 135 13054-13061. (doi:10.1021/ja405475y)

Kemp S, Wheate NJ, Buck DP, Nikac M, Collins JG \& Aldrich-Wright JR 2007 The effect of ancillary ligand chirality and phenanthroline functional group substitution on the cytotoxicity of platinum(II)-based metallointercalators. Journal of Inorganic Biochemistry 101 1049-1058. (doi:10.1016/j.jinorgbio.2007.04.009)

Khalaila I, Allardyce CS, Verma CS \& Dyson PJ 2005 A mass spectrometric and molecular modelling study of cisplatin binding to transferrin. Chembiochem 6 1788-1795. (doi:10.1002/cbic.200500067)

Kirkpatrick GJ, Plumb JA, Sutcliffe OB, Flint DJ \& Wheate NJ 2011 Evaluation of anionic half generation 3.5-6.5 poly(amidoamine) dendrimers as delivery vehicles for the active component of the anticancer drug cisplatin. Journal of Inorganic Biochemistry 105 1115-1122. (doi:10.1016/j.jinorgbio.2011.05.017)

Kozubík A, Horváth V, Švihálková-Šindlerová L, Soucek K, Hofmanová J, Sova P, Kroutil A, Žák F, Mistr A \& Turánek J 2005 High effectiveness of platinum(IV) complex with adamantylamine in overcoming resistance to cisplatin and suppressing proliferation of ovarian cancer cells in vitro. Biochemical Pharmacology 69 373-383. (doi:10.1016/j.bcp.2004.09.005)

Krause-Heuer AM, Wheate NJ, Tilby MJ, Pearson D, Ottley CJ \& AldrichWright JR 2008 Substituted $\beta$-cyclodextrin and calix[4]arene as encapsulatory vehicles for platinum(II)-based DNA intercalators. Inorganic Chemistry 47 6880-6888. (doi:10.1021/ic800467c)

Lao Y-H, Phua KKL \& Leong KW 2015 Aptamer nanomedicine for cancer therapeutics: Barriers and potential for translation. ACS Nano 9 2235-2254. (doi:10.1021/nn507494p)

Li J, Pant A, Chin CF, Ang WH, Menard-Moyon C, Nayak TR, Gibson D, Ramaprabhu S, Panczyk T, Bianco A \& Pastorin G 2014 In vivo biodistribution of platinum-based drugs encapsulated into multiwalled carbon nanotubes. Nanomedicine : Nanotechnology, Biology, and Medicine 10 1465-1475. (doi:10.1016/j.nano.2014.01.004)

Liu K-J, Guan Z-Z, Liang Y, Yang X-Q, Peng J, Huang H, Qing-Xiang S, Meng-Zhao W, Zhu Y-Z, Wu C-P et al. 2014 A double-blind, randomized phase II study of dicycloplatin plus placlitaxel versus carboplatin plus paclitaxel as first-line therapy for patients with advanced non-smallcell lung cancer. Archives of Medical Science 10 717-724. (doi:10.5114/ aoms.2014.44862)

Luo L-Z, Jin H-W \& Huang H-Q 2012 Transferrin-cisplatin specifically deliver cisplatin to HepG2 cells in vitro and enhance cisplatin cytotoxicity. Journal of Proteomics $\mathbf{7 7}$ 237-250. (doi:10.1016/j.jprot. 2012.08.023)

Ma H, Liu J, Ali MM, Mahmood MAI, Labanieh L, Lu M, Iqbal SM, Zhang Q, Zhao W \& Wan Y 2015 Nuclei acid aptamers in cancer research, diagnosis and therapy. Chemical Society Reviews 44 1240-1256. (doi:10.1039/C4CS00357H)

Mahdavifar Z \& Moridzadeh R 2014 Theoretical prediction of encapsulation and adorption of platinum-anticancer drugs into single walled boron nitride and carbon nanotubes. Journal of Inclusion Phenomena and Macrocyclic Chemistry 79 443-457. (doi:10.1007/s10847-013-0367-1)

Mai J, Song S, Rui M, Liu D, Ding Q, Peng J \& Xu Y 2009 A synthetic peptide mediated active targeting of cisplatin liposomes to Tie2 expressing cells. Journal of Controlled Release 139 174-181. (doi:10.1016/j.jconrel. 2009.06.024)

Massaguer A, Gonzalez-Canto A, Escribano E, Barrabes S, Artigas G, Moreno V \& Marchan V 2015 Integrin-targeted delivery into cancer cells of a Pt(IV) pro-drug through conjugation to RGD-containing peptides. Dalton Transactions 44 202-212. (doi:10.1039/C4DT02710H)

McGinely NL, Plumb JA \& Wheate NJ 2013 DNA-b, based aptamer fails as a simultaneous cancer targeting agent and drug delivery vehicle for a phenanthroline-based platinum(II) complex,. Journal of Inorganic Biochemistry 128 124-130. (doi:10.1016/j.jinorgbio.2013.07.021)

Mejri A, Vardanega D, Tangour B, Gharbi T \& Picaud F 2015 Encapsulation into carbon nanotubes and release of anticancer cisplatin drug molecule. Journal of Physical Chemistry. B 119 604-611. (doi:10.1021/ jp5102384)

Moghaddam S, Yang C, Rekharsky M, Ko YH, Kim K, Inoue Y \& Gilson MK 2011 New ultrahigh affinity host-guest complexes of cucurbit[7]uril with bicyclo[2.2.2]octane and adamantane guests: thermodynamic analysis and evaluation of M2 affinity calculations. Journal of the American Chemical Society 133 3570-3581. (doi:10.1021/ja109904u)

Moghaddas S, Majmudar P, Marin R, Dezvareh H, Qi C, Soans E \& Bose RN 2012 Phosphaplatins, next generation platinum antitumor agents: a paradigm shift in designing and defining molecular targets. Inorganica Chimica Acta 393 173-181. (doi:10.1016/j.ica.2012.05.040)

Nguyen H, Nguyen NH, Tran NQ \& Nguyen CK 2015 Improved method for preparing cisplatin-dendrimer nanocomplex and its behavior against NCi-H460 lung cancer cell. Journal of Nanoscience and Nanotechnology $\mathbf{1 5}$ 4106-4110. (doi:10.1166/jnn.2015.9808)

Osman AA, Neskey DM, Katsonis P, Patel AA, Ward AM, Hsu T-K, Hicks SC, McDonald TO, Ow TJ, Alves MO et al. 2015 Evoluntionary action score of TP53 coding variants is predictive of platinum response in head and neck cancer patients. Cancer Research 75 1205-1215. (doi:10.1158/ 0008-5472.CAN-14-2729)

Oun R, Floriano RS, Isaacs L, Rowan EG \& Wheate NJ 2014 The ex vivo neurotoxic, myotoxic and cardiotoxic activity of cucurbituril-based macrocyclic drug delivery vehicles. Toxicology Research 3 447-455. (doi:10.1039/C4TX00082J)

Panczyk T, Jagusiak A, Pastorin G, Ang WH \& Narkiewicz-Michalek J 2013 Molecular dynamics study of cisplatin release from carbon nanotubes capped by magnetic nanoparticles. journal of Physical Chemistry. C, Nanomaterials and Interfaces 117 17327-17336. (doi:10.1021/ jp405593u)

Park GY, Wilson JJ, Song Y \& Lippard SJ 2012 Phenanthriplatin, a monofunctional DNA-binding platinum anticancer drug candidate with unusual potency and cellular activity profile. PNAS $\mathbf{1 0 9}$ 11987-11992. (doi:10.1073/pnas.1207670109)

Pisani MJ, Wheate NJ, Keene FR, Aldrich-Wright JR \& Collins JG 2009 Anionic PAMAM dendrimers as drug delivery vehicles for transition

Published by Bioscientifica Ltd 
metal-based anticancer drugsAnionic PAMAM. Journal of Inorganic Biochemistry 103 373-380. (doi:10.1016/j.jinorgbio.2008.11.014)

Plumb JA, Venugopal B, Oun R, Gomez-Roman N, Kawazoe Y, Venkataramanan NS \& Wheate NJ 2012 Cucurbit[7]uril encapsulated cisplatin overcomes cisplatin resistance via a pharmacokinetic effect. Metallomics 4 561-567. (doi:10.1039/c2mt20054f)

Poland CA, Duffin R, Kinloch I, Maynard A, Wallace WAH, Seaton A, Stone V, Brown S, MacNee W \& Donaldson K 2008 Carbon nanotubes introduced into the abdominal cavity of mice show asbestos-like pathogenicity in a pilot study. Nature Nanotechnology 3 423-428. (doi:10.1038/nnano.2008.111)

Prashar D, Shi Y, Bandyopadhyay D, Dabrowiak JC \& Luk Y-Y 2011 Adamantane-platinum conjugate hosted in b-cyclodextrin: enhancing transport and cytotoxicity by noncovalent modification. Bioorganic \& Medicinal Chemistry 21 7421-7425. (doi:10.1016/j.bmcl.2011.10.006)

Pulskamp K, Woerle-Knirsch JM, Hennrich F, Kern K \& Krug HF 2007 Human lung epithelial cells show biphasic oxidative burst after single walled carbon nanotube contact. Carbon 45 2241-2249. (doi:10.1016/j. carbon.2007.06.054)

Pur FN \& Dilmaghani KA 2014 Calixplatin: novel potential anticancer agent based on the platinum complex with functionalized calixarene. Journal of Coordination Chemistry 67 440-448. (doi:10.1080/00958972. 2014.890718)

Rolland O, Turrin C-O, Caminade A-M \& Majoral J-P 2009 Dendrimers and nanomedicine: multivalency in action. New Journal of Chemistry 33 1793-1980. (doi:10.1039/b901054h)

Rowe RC, Sheskey PJ, Look WG \& Fenton ME 2012 Handbook of Pharmaceutical Excipients, 7th edn. London, UK: Pharmaceutical Press.

Ruggiero A, Trombatore G, Triarico S, Arena R, Ferrara P, Scalzone M, Pierri F \& Riccardi R 2013 Platinum compounds in children with cancer: toxicity and clinical management. Anti-Cancer Drugs $\mathbf{2 4}$ 1007-1019. (doi:10.1097/CAD.0b013e3283650bda)

Sanchez-Paradinas S, Perez-Andres M, Almendral-Parra MJ, RodriguezFernandez E, Millan A, Palacio F, Orfao A, Criado JJ \& Fuentes M 2014 Enhanced cytotoxic activity of bile acid cisplatin derivatives by conjugation with gold nanoparticles. Journal of Inorganic Biochemistry 131 8-11. (doi:10.1016/j.jinorgbio.2013.10.021)

Sava G \& Dyson PJ 2006 Metal-based antitumour drugs in the post genomic era. Dalton Transactions 16 1929-1933. (doi:10.1039/B601840H)

Seif M, Impelido ML, Apps MG \& Wheate NJ 2014 Topical cream-based dosage forms of the macrocyclic drug delivery vehicle cucurbit[6]uril. PLOS ONE 9 e85361. (doi:10.1371/journal.pone.0085361)

Shangguan D, Tang Z, Mallikaratchy P, Xiao Z \& Tan W 2007 Optimization and modifications of aptamer selected from live cancer cell lines. Chembiochem 8 603-606. (doi:10.1002/cbic.200600532)

Shi Y, Goodisman J \& Dabrowiak JC 2013 Cyclodextrin capped gold nanoparticles as a delivery vehicle for a prodrug of cisplatin. Inorganic Chemistry 52 9418-9426. (doi:10.1021/ic400989v)

Stathopoulos GP \& Boulikas T 2012 Lipoplatin formulation review article. Journal of Drug Delivery article 581363. (doi:10.1155/2012/581363)

Tekade RK, Kumar PV \& Jain NK 2009 Dendrimers in oncology: an expanding horizon. Chemical Reviews 109 49-87. (doi:10.1021/ cr068212n)

Torchilin V 2011 Tumour delivery of macromolecular drugs based on the EPR effect. Advanced Drug Delivery Reviews 63 131-135. (doi:10.1016/j. addr.2010.03.011)

Veal GJ, Dias E, Price E, Parry A, Errington J, Hale J, Pearson ADJ, Boddy AV, Newell DR \& Tilby MJ 2001 Influence of cellular factors and pharmacokinetics on the formation of platinum-DNA adducts in leukocytes of children receiving cisplatin therapy. Clinical Cancer Research 7 2205-2212.

Waalboer DCJ, Muns JA, Sijbrandi NJ, Schasfoort RBM, Haselberg R, Somsen GW, Houthoff H-J \& van Dongen GAMS 2015 Platinum (II) as a bifunctional linker in antibody-drug conjugate formation: coupling of a 4-nitrobenzo-2-oxa-1,3diazole fluorophore to trastuzumab as a modelPlatinum II),. ChemMedChem 10 797-803. (doi:10.1002/cmdc. 201402496)

Wagstaff AJ, Brown SD, Holden MR, Craig GE, Plumb JA, Brown RE, Schreiter N, Chrzanowski W \& Wheate NJ 2012 Cisplatin drug delivery using gold-coated iron oxide nanoparticles for enhanced tumour targeting with external magnetic fields. Inorganica Chimica Acta 393 328-333. (doi:10.1016/j.ica.2012.05.012)

Walker S, Kaur R, McInnes FJ \& Wheate NJ 2010 Synthesis, processing and solid state excipient interactions of cucurbit[6]uril and its formulation into tablets for oral drug delivery. Molecular Pharmacology 7 2166-2172. (doi:10.1021/mp100191b)

Walker S, Oun R, McInnes FJ \& Wheate NJ 2011 The potential of cucurbiturils in drug delivery. Israel Journal of Chemistry $\mathbf{5 1}$ 616-624. (doi:10.1002/ijch.201100033)

Wexselblatt E \& Gibson D 2012 What do we know about the reduction of Pt(IV) pro-drugs? Journal of Inorganic Biochemistry 117 220-229. (doi:10.1016/j.jinorgbio.2012.06.013)

Wheate NJ 2008 Improving platinum(II)-based anticancer drug delivery using cucurbit[n]urils. Journal of Inorganic Biochemistry 102 2060-2066. (doi:10.1016/j.jinorgbio.2008.06.005)

Wheate NJ, Taleb RI, Krause-Heuer AM, Cook RL, Wang S, Higgins VJ \& Aldrich-Wright JR 2007 Novel platinum(II)-based anticancer complexes and molecular hosts as their drug delivery vehicles. Dalton Transactions 43 5055-5064. (doi:10.1039/b704973k)

Wheate NJ, Abbott GM, Tate RJ, Clements CJ, Edrada-Ebel R \& Johnston BF 2009 Side-on binding of $p$-sulphonatocalix[4]arene to the dinuclear platinum complex trans-[\{PtCl(NH3)2) $2 \mathrm{u}-\mathrm{dpzm}]^{2+}$ and its implications for anticancer drug delivery. Journal of Inorganic Biochemistry 103 448-454. (doi:10.1016/j.jinorgbio.2008.12.011)

Wheate NJ, Walker S, Craig GE \& Oun R 2010 The status of platinum anticancer drugs in the clinic and in clinical trials. Dalton Transactions 39 8113-8127. (doi:10.1039/c0dt00292e)

Xia W \& Low PS 2010 Folate-targeted therapies for cancer. Journal of Medicinal Chemistry 53 6811-6824. (doi:10.1021/jm100509v)

Xu H, Robinson GW, Huang J, Lim JY-S, Zhang H, Bass JK, Broniscer A, Chintagumpala M, Bartels U, Gururangan S et al. 2015 Common variants in ACYP2 influence susceptibility to cisplatin-induced hearing loss. Nature Genetics 47 263-266. (doi:10.1038/ng.3217)

Yu JJ, Yang X, Song Q, Mueller MD \& Remick SC 2014 Dicycloplatin, a novel platinum analog in chemotherapy: synthesis of chinese preclinical and clincal profile and emerging mechanistic studies. Anticancer Research 34 455-464.

Zalba S \& Garrido MJ 2013 Liposomes, a promising strategy for clinical application of platinum derivatives. Expert Opinion on Drug Delivery 10 829-844. (doi:10.1517/17425247.2013.778240)

Zhao Y, Bali MS, Cullinane C, Day AI \& Collins JG 2009 Synthesis, cytotoxicity and cucurbituril binding of triamine linked dinuclear platinum complexes. Dalton Transactions 26 5190-5198. (doi:10.1039/ b905112k)

Zhao M-X, Zhao M, Zeng E-Z, Li Y, Li J-M, Cao Q, Tan C-P, Ji L-N \& Mao Z-W 2014 Enchanced anti-cancer efficacy to cancer cells by doxorubicin loaded water-soluble amino acid-modified $\beta$-cyclodextrin platinum complexes. Journal of Inorganic Biochemistry 137 31-39. (doi:10.1016/j.jinorgbio.2014.03.012)

Received in final form 16 June 2015

Accepted 23 June 2015

Made available online as an Accepted Preprint

25 June 2015 http://erc.endocrinology-journals.org

DOI: 10.1530/ERC-15-0237
(C) 2015 Society for Endocrinology Printed in Great Britain
Published by Bioscientifica Ltd. 